\title{
It takes more than Moore to answer existence-questions
}

\begin{abstract}
Several recent discussions of metaphysics disavow existence-questions, claiming that they are metaphysically uninteresting because trivially settled in the affirmative by Moorean facts. This is often given as a reason to focus metaphysical debate instead on questions of grounding. I argue that the strategy employed to undermine existence-questions fails against its usual target: Quineanism. The Quinean can protest that the formulation given of their position is a straw man: properly understood, as a project of explication, Quinean metaphysics does not counsel us to choose between obvious ordinary-language claims and absurd revisionist claims, even if appeal to Moorean facts is permitted.

Keywords: Moorean fact ; explication ; Quine ; metametaphysics ; existence
\end{abstract}

\section{Quineanism and the Moorean challenge}

Much recent work in metametaphysics seeks to undermine what has been described as the 'preferred methodology' (Manley 2009, 3) for dealing with ontological ques- 
tions: Quineanism. There is much to be said about what exactly this approach is (or should be), ${ }^{1}$ but one strand of agreement is that for the Quinean, 'ontological questions are quantificational questions' (Fine 2009, 158). That is, ontology is concerned with what we quantify over, or equivalently (for the Quinean), what there is, or again equivalently (for the Quinean), what exists. For a putative kind $F$, we can ask any of the following:

- Are there Fs?

- Do Fs exist?

- Is it the case that $\exists x(F x)$ ?

However a range of metaphysicians, starting with Kit Fine $(2001,2009)$ but including with some variation Jonathan Schaffer (2009) and Kathrin Koslicki (2012; 2016), envisage a serious problem with treating questions of this form as central to ontology. ${ }^{2}$ They claim that for almost any reasonable candidate, the questions resulting from its substitution into the schemas above are trivially answerable in the affirmative. To take some typical examples of how to obtain these easy answers:

\section{Numbers}

(1) There are prime numbers.

(2) Therefore, there are numbers.

\section{Properties}

(1) There are properties that you and I share.

(2) Therefore, there are properties. 
This argumentative strategy has been described by Schaffer as Moorean. In each case the premise is claimed to be a Moorean fact, 'one of those things that we know better than we know the premises of any philosophical argument to the contrary' (Lewis 1996, 549), whose truth establishes the conclusion because the conclusion is a weakening of the premise. Contrariwise, by considering the question whether there are numbers, or propositions, the Quinean is enquiring after something whose falsity would entail the falsity of a Moorean fact. But, says the endorser of this strategy, it's a Moorean fact! We are so confident that it is a fact that no argument to the contrary should move us.

These examples do not in themselves show that the Quinean approach is untenable. The central move for what I will call the triviality argument generalises on the examples, reasoning as follows. Most questions of the form "Are there Fs?" that the Quinean regards as interesting can, they say, be answered by appeal to Moorean facts. They then claim that if such a question can be answered by appeal to a Moorean fact, it is uninteresting, and therefore that the questions regarded as interesting by the Quinean are in fact uninteresting. ${ }^{3}$ On the assumption that an approach is flawed if it seriously misrepresents the questions it considers, the proponent of the triviality argument rejects Quineanism.

There are at least two simple ways that a Quinean could respond. First they might insist that there is at least one substitution of $F$ for which no Moorean fact undermines the existence question, but proponents of the triviality argument will be happy to issue the challenge and wait for counterexamples. If one is proposed, they may still attempt to take recourse in Moorean facts, pitting their own intuitions against those of the Quinean, but this is not necessary. This is 
because they need not hold that one can never pursue the Quinean strategy; they can rest content with the more limited thesis that 'one should be permissive about those very entities Quineans typically consider most controversial' (Schaffer 2009, 359). For instance, Fine $(2009,158)$ admits that possible worlds may be an exception to the triviality argument because 'possible world' is a philosophical term of art about which most people have no intuitions, and Schaffer claims that putative kinds will not be amenable to Moorean existence-proofs if their definitions presuppose their fundamentality because he sees that as smuggling in content from other metaphysical approaches. ${ }^{4}$ Neither thinks that these exceptions undermine the strategy, and this is primarily because they contend that, even if there are a handful of legitimate Quinean ontological questions, there are a great many more important ontological questions not addressed by that approach, making the Quinean approach at best a sideshow. The contention of the Quinean is supposed to be that they identify the, or at least the main, methodology for metaphysics. The moderate response of seeking exceptions to the Moorean move is therefore ineffective.

The second simple Quinean response is to insist that Quineanism has ontology right but to just concede that, as it turns out, there aren't really any interesting ontological questions. Typically defenders of the triviality argument say that there obviously are interesting ontological questions and we need to find a way to acknowledge this, so they go on to articulate some version of 'neo-Aristotelianism', locating the ontological project instead in questions about whether, and how, entities are grounded in other entities. However versions of the triviality argument have been endorsed by philosophers who would describe themselves as deflation- 
ists, ${ }^{5}$ for whom the dearth of interesting ontological questions is a welcome result. From the Quinean's perspective, though, this would be a rather unsatisfying response.

There have been sophisticated responses (though surprisingly few) to the triviality argument. For instance Daly and Liggins (2014) argue that nothing has been done to establish the Moorean status of the examples in the triviality argument, and therefore that we lack any reason to deny that any countervailing considerations could be strong enough to undermine it, even if we concede that each starting premise possesses strong warrant. I will not contribute further to criticism of that premise of the triviality argument, though I think that a defence from the perspective of confirmation holism is rather persuasive ${ }^{6}-\mathrm{I}$ will instead grant for the sake of argument that the statements in question are Moorean facts. Nor am I interested in critiquing the neo-Aristotelian approach offered to replace Quineanism, both because this would do nothing to respond to the aforementioned deflationists for whom the triviality argument leads to a different conclusion, and because there is already a large and complex literature on how (if at all) we can make sense of grounding.

My strategy will instead be to criticise the formulation of the Quinean approach that has been used to construct the triviality argument. By failing to articulate the approach clearly, I argue, these philosophers get away with ignoring better explanations of debates from the target perspective: in particular, the Quinean can easily deny that it follows from the availability of an answer to "Are there Fs?" by appeal to Moorean facts that the question is uninteresting. 


\section{Elimination and explication}

The presentation of this issue by proponents of the triviality argument presupposes that the Quinean focus when asking ontological questions is on challenging, and potentially throwing out, putative kinds of entity. Accordingly critiques of Quineanism are sometimes treated in the same breath as critiques of 'eliminativism' ${ }^{7}$ with an attendant focus on the (il)legitimacy of eliminating from our account entities that are identified as problematic.

A simple picture of this endeavour would show us starting with a list of kinds $\{F, G, H, I, J, \ldots\}$ and, suspicious of, for instance, $I$, seeking arguments against its existence that are strong enough to jettison it from the list, clearing out the clutter from our ontology in search of a 'desert [landscape]' (Quine 1948, 23). We eventually find ourselves with a shortened list, say, $\{F, H, J\}$. This is the endpoint Schaffer describes when explaining that the Quinean conception of ontology is flat: 'The target of metaphysical inquiry is an unstructured list of existents E. ${ }^{\prime 8}(2009$, 355) In contrast Schaffer's preferred view is of the target of metaphysical enquiry as a hierarchy - we should end up with a structure that maps out groundingrelations from the most derivative entities to the most fundamental. For him, giving a Quinean ontology is much like describing a house just by listing its parts: it constitutes a poor account because we lack an explanation of the structural relations.

But Schaffer is wrong to think this. For the Quinean the target of metaphysical enquiry is not just an ontology as a list of accepted kinds, but an ontology with an accompanying ideology. This notion, introduced in Quine (1951), refers to 'one's stock of simple and complex terms or predicates' (Quine 1983, 501), and concerns 
what can be expressed in a theory. Alongside the question of what things we say there are is the question of what notions we we need in order to talk about them. Indeed unless we rely on ostension to identify all the objects of our theory (which comes with its own serious problems), ideology is essential to our ability to formulate an ontology at all. When I make any claim about the metaphysics of $F$ s, I'd better be able to explain what $F$ s are like.

I anticipate the following reply:

"So what? Re-phrase and say that the target of Quinean ontological enquiry is an unstructured list of existents. It remains true that the Quinean countenances absurd possibilities, so their metaphysics collapses thanks to its reliance on a bad conception of ontology."

However, the introduction of ideology in fact changes things substantially, for the Quinean will regard ontology and ideology as closely related: there will be no such thing as ontological enquiry divorced from ideological enquiry because we are constantly engaged in a complex trade-off between the two. Providing fully instructive examples proves difficult since in any dispute concerning a specific kind $K$, whether something constitutes an ontological or ideological cost will depend on what has already been accepted elsewhere in the theory. However a reasonable example would be in the debate between platonism and fictionalism about mathematics - being free of numbers adds an ideological counterbalance of mathematical fiction operators, while being burdened with numbers frees us from the weight of those operators. Another might be presented by a dispute about the existence of states - one can deny that states exist, but may incur an ideological cost of explaining certain phenomena like declarations of war or state oppression. 
It should be borne in mind that the trade-off described above is not always direct, since we might have two theories with the same ontology but different ideologies. ${ }^{9}$ Thus we shouldn't expect an itemised list of debates with "Ontology or ideology?" affixed to each. A simple comparison would be between a theory accepting primitive modal operators and one rejecting them; assuming there was no difference in ontology between the two, this would mean that the latter theory was forced to reject all modal language. Of course in this case, barring serious reasons for doubt about modal idioms as a whole, the comparison that will occupy metaphysicians for longer is that between modality as ideological (in terms of operators) and as ontological (in terms of possible worlds). ${ }^{10}$

Furthermore, this reveals the character of the misrepresentation of Quineanism: the Quinean metaphysical project is one of explication, specifically (if we want to be truly Quinean) explication of all of our serious linguistic behaviour. A formulation of which Quine approved glosses this as 'making more exact a vague or not quite exact concept used in everyday life' (Carnap 1947, 8); we are generally not looking for dubious kinds to throw out of our account of the world because they fail to meet some authoritative standard of reality, we are seeking to clarify our account of the world as we understand it and seeing what kinds are needed to do so. To paraphrase the now-cliché Quinean quip, the relevant three Anglo-Saxon monosyllables are not "Are there Fs?", but "What is there?" (Quine 1948). If we imagined the enquirer as progressively introducing language ranging over different kinds of entity until able to achieve with their theory everything that we can in fact achieve, the question of elimination would not come up, or would at best be secondary to the constructive project. This is not to say that for Quine the project 
is essentially constructive, but rather that on Quine's view we could choose either way, constructive or destructive, of framing the very same project. More on this later.

This way of considering things might seem to make no difference in part because of a well-known passage of Quine where he states that '[e]xplication is elimination but not all elimination is explication' Quine 1960, §53). This suggests on first reading that explication is for him a subtype of elimination, and therefore that elimination is the category of real interest - this view would have it that explication simply reduces to a special case of elimination. However what Quine goes on to say on this matter is informative, since the determining factor in whether an elimination counts as an explication is how far usage before the project maps onto usage after it. This is a difference of degree rather than a difference in kind, and this is significant because most would regard explication as a different sort of project from elimination. ${ }^{11}$

The fact that Quine regards them as the same sort of project reveals his attitude: that we cannot think of ourselves as trying to pick out which of our terms correspond to the real things, but rather we must think of ourselves as engaged in a project of identifying good ways to construct a theory. We say 'elimination' when the good way we find is radically different from the way we started; we say 'explication' when the good way we find isn't offensive to our starting position. This difference in phrasing is not because there are two projects - there is just one which can be described in multiple ways. However we seek to characterise it differently depending on features displayed in the part of the project we're engaged in. Out of appreciation for the fact that a successful explication will often 
involve a 'partial parallelism of function' (Quine 1960, 261) between the old way of speaking and the new, the two characterisations are useful for picking apart when an account shows less or more of such parallelism.

In saying this I am rejecting the view espoused implicitly by many writing about Quinean methodology that Quine's central concern is not explication but regimentation. ${ }^{12}$ That regimentation cannot capture the Quinean project should be clear: after regimenting our language we will be left with the question of which theory best achieves our goals, and we would be remarkably fortunate to find that the way in which we tidied up usage turned out to be most useful. When we find ourselves in this position, our best recourse will be in explication.

Of course we should accept that the constructive view is not the one we typically take when we do ontology. Given the inevitable complexity of whatever overall theory we arrive at, we typically start by identifying problematic kinds in the theory that we bring to the table, and this might be taken to place eliminativism front-and-centre again. However, to see why focussing on elimination is still misleading, we can turn to the notions of explaining and explaining away, on which Quine's stance is notably similar to the above. ${ }^{13}$ These are often treated as distinct, and in at least one sense they certainly are. Something might be described as having been explained when that explanation is only partial; for instance my being hungry explains why I'm looking through the fridge even though it is by no means a complete explanation of my looking through the fridge (I am hungry a lot of the time, and only most of the time does it result in a rifling through the fridge). In contrast, nothing would be regarded as explained away without being completely so. I do not count as having explained away the ghost 
at the fairground if I can account for all spooky goings-on as actions taken by a nefarious property developer who wants it shut down except for the sighting that took place while she was out of town.

However, if we countenance only complete explanations, it's less clear that the two notions are distinct and for the true Quinean their difference is simply one of emphasis. On the project to eliminate mental entities, Quine writes:

The reduction of the mental to the physical. . can be characterized in either of two ways: as explaining or as explaining away. There is no difference, but the first phrasing has a gentler ring. To have repudiated the life of the mind seems harsher than to have explained it in physical terms. Quine 1995, 86, emphasis in original)

If explaining and explaining away are in all important respects equivalent, then as Gustafsson (2006) points out, the same follows for elimination and identification, and this means that 'Quine is an eliminativist only in a rather unusual sense of the word' (Gustafsson 2006, 58), if at all. Focussing on elimination is therefore misleading: it privileges a less natural statement of the situation over a statement given in terms congenial to the intuitions that the triviality argument seeks to exploit.

\section{No Moore argument}

We can now clearly show how the proponent of the triviality argument misrepresents the Quinean approach in the key cases. Recall Properties: the argument's strategy looks effective because it challenges the Quinean to dare consider ques- 
tioning (2), aware that to do so seems to be to entertain the possibility of the rejection by modus tollens of a Moorean fact. Suppose that (1) is a Moorean fact. It nonetheless does not follow that the argument shows the Quinean approach to treat trivial points as substantial because the fact's Moorean status does not by any means fix its analysis. Moore himself was aware of this: he claimed to refute idealism and prove the existence of an external world by appeal to the Moorean fact expressed by "I know that I have hands", but while he thought this sufficient for his purposes, he remained 'very sceptical as to what, in certain respects, the correct analysis of such propositions is ${ }^{14}$ (Moore 1959, §4).

Given therefore that we remain open to analysis, there is nothing to rule out the following extension to Properties:

(3) Properties just are sets.

(4) Therefore, there are no properties over and above sets.

This is an eliminative argument, assuming that we have accepted sets, because we remove the commitment to any entity beyond a set of objects sharing a feature, but it does not deny the Moorean fact. By presenting the argument as explaining what properties are, we preserve the truth of (2). ${ }^{15}$ We of course need some argument for accepting (3), but that lies beyond my remit (I have no stake here in the status of properties and sets in particular).

The Quinean's opponent might think they have a legitimate gripe with (4), saying that if we are to understand 'nothing over and above' claims, we need to make use of a serious notion of grounding. This line of thought would have it that (4) means something like "Properties are grounded in sets." Since the Quinean will not engage with such questions, they cannot employ premises like (4), so the 
argument will go.

However the Quinean can reasonably point out that they don't mean anything special by statements like (4). For them this is a matter of phrasing that indicates a closer connection between explicatum and explicandum than might be seen in other cases. It has no special content beyond a statement like "There is no such person as Superman over and above Clark Kent," where that is understood as a way of saying that they are the same person. Depending on the confusion one seeks to clear up, another way of saying the same would be to say "There is no Superman, just Clark Kent" (though we might avoid this phrasing for fear of suggesting that the subject's superpowers were spurious).

The inclusion of ideology in our enquiry demonstrates further how such extensions can leave an interesting question. For an easy example demonstrating its relevance:

\section{Couples}

(1) Some couples are closer than others.

(2) Therefore, there are couples.

(3) Couples just are two people satisfying the predicate ' $x x$ are together'.

(4) Therefore, there are no couples over and above people quantified over plurally.

Whether this is an acceptable argument turns on questions of ideology - if we countenance both plural and singular quantification, we can account for couples in ideological terms, but if we do not regard plural quantification as basic a different strategy must be employed (which isn't to say that there aren't good 
examples of such strategies). The proponent of the triviality argument, on the other hand, cannot avoid an ontologically committing interpretation of "There are couples," because of their heavyweight interpretation of the Moorean fact; indeed Fine $(2009,160)$ endorses this move explicitly (and thereby invites questions about fundamentality and ground with respect to couples). Others might insist that Couples involves no Moorean fact, but it is hard to know how this might be defended without undermining the Mooreanness of Properties, insofar as both arguments just appeal to ordinary language.

A task remains for us, though: how can we understand the apparent contrast between explaining and explaining away? On the Quinean picture, why would we prefer one characterisation over the other? The quote above discouraging any serious distinction between the two suggested that this question is not worth asking, but such a dismissal is only uncontroversial from within the Quinean framework. In the face of the external challenge posed by the triviality argument it is important that we say more to motivate the Quinean view of the relationship between the notions.

Quine is not always helpful in this respect: at least in the above passage he prefers to describe the physical as explaining the mental, while he describes classes as explaining away the natural numbers, but dedicates little space to justifying the distinction. The considerations he offers relate to the presence of alternative analyses: we have a fairly stable physical story that purports to do the explanatory work of the mental, ${ }^{16}$ while numbers can be successfully identified with various different structures, so distaste for saying that 2 is the class of all pairs and the class containing exactly 0 and 1 leads him to prefer the eliminative characterisation. 
However we can give a more general reason to choose between the formulations that demonstrates why the Quinean does not err in considering them more-or-less equivalent. This will show why, though Quine is remiss for insufficiently explaining his rejection of a serious distinction, the oversight is understandable - the result falls out of his basic methodology.

As mentioned above, the Quinean is engaged in a project of explication: based on the broad base of language use that we must take to be correct to make sense of anything at all, we attempt to clarify what we're talking about in a way that goes beyond our mere speech behaviour. The outcome of explication will sometimes be surprising from the standpoint of the naive defender of a putative kind, and sometimes will not, and this in turn will often have a great deal to do with the role played by the original term in our theory. When the outcome furnishes surprises, explaining away is the natural characterisation of a successful theory, while when it doesn't it is best seen as merely explaining. Yet again, though, this does not bespeak a sharp, principled difference.

For instance, suppose we are enquiring about universals and we find that the phenomena they are employed to explain are dealt with adequately by the existence of sets. Defenders of universals would typically say that we should believe in universals because without entities possessing their distinctive features we cannot make sense of talk about shared features at all, so if the phenomena in question (shared features) are adequately explained by sets it would be strange to retain the term of art 'universal' and say that, as it turns out, universals just are sets. Compare this to a superficially similar enquiry about properties. In this situation, were we to find sets sufficient to explain the phenomena for which properties 
seemed necessary (again, talk of shared features), it would be more natural to regard our account as explaining what properties are because nothing substantial or controversial is intimately associated with the term. It wouldn't be unreasonable to hold the concept property to pick out whatever explains the co-attribution of predicates. ${ }^{17}$

The proponent of the triviality argument will perhaps protest that we have not really shown how the Quinean can have an interesting ontological project. It is not my task to do so fully here, as demonstrating this would require substantial further commitments. My aim has been to show, without relying on any particular contentious ontological claims, that one may accept the Moorean facts advanced by the triviality argument without conceding that the Quinean approach must then fail by treating as questionable that which is certain.

However we have seen, albeit briefly, how the Quinean can have an interesting ontological enquiry. Assuming a Moorean fact that says or entails "There are Fs", the wider Quinean ontological project becomes relevant to questions about the kind $F$ when we ask whether there are statements in our prospective theory, Moorean or otherwise, of the form "There are $G \mathrm{~s}$ " such that we could plausibly identify the kinds $F$ and $G$. To gesture at how the project will continue we can look to ideology, both in the basic sense of our accepted logical notions and in a wider sense. For instance, once we have accepted "There are properties" there remains the question what predicates apply to those entities: for instance, should we hold that the predicate " $x$ resides in Platonic heaven" applies to them? Our eliminative extension to Properties would then turn the question about that predicate on to sets themselves, a simple example of the interaction of the 
ontological and ideological projects. I have not provided details of how one would resolve these further questions, but again that is not my task here, especially as it might undermine our current neutrality between various approaches to ontology.

\section{Conclusion}

I conclude that the triviality argument does not show the Quinean approach to be fatally flawed, even if we grant the assumption that a wide range of existencestatements are Moorean facts. The Quinean can, in cases that do not clash with core usage, regard an account as merely explaining the entities involved by identifying them with other entities or by showing them to be ideological constructions. ${ }^{18}$

\section{Notes}

1 van Inwagen $(1998,2009)$ attempts to articulate the Quinean approach, and some instructive analysis can be found from Eklund (2006a|b) and Jenkins (2010), but these sources enjoy only partial agreement, and Eklund and Jenkins acknowledge unresolved tensions between Quineanism and Quine's work. Other work from a range of perspectives ( Hylton (2007); Price (2009); Ebbs (2011); Egerton (2016)) attempts to directly uncover failings in previous understandings of Quine's work and its implications for metaphysics.

${ }^{2}$ Koslicki goes further and directly attributes the same failure to Carnap's approach. This combined attack may be especially appropriate given the emerging idea that Quine and Carnap should be seen as far less opposed than they have customarily been portrayed; while I will not explore this in detail here, the discussion in $\S 2$ of explication is also telling since Quine took that notion on from Carnap.

${ }^{3}$ I will not attempt to define 'interesting' and 'uninteresting' in this context; I assume that it is sufficiently clear for our current purposes. 
${ }^{4}$ This is important to Schaffer because given his radical permissivism about existence questions he would risk collapsing grounding- and fundamentality-based accounts were he to treat 'There are fundamental- $F \mathrm{~s}$ ' as easily answerable in the same way as 'There are $F \mathrm{~s}$ '.

${ }^{5}$ I have in mind here Hirsch (2005) and Thomasson (2007), although each of their accounts involves separate considerations from the triviality argument which I will not address here. For critical discussion of Thomasson's approach in particular, see Egerton (2018).

${ }^{6}$ In brief, a defence from this perspective would be to say that since any statement is in principle revisable (should this prove necessary to avoid disturbance to the rest of the theory), we cannot rule out a change to these beliefs. Note that this need not mean that we rely on an implausible direct U-turn on the statement "There are numbers" itself, since that would play into the hands of proponents of the triviality argument. In fact any number of other connected beliefs might be the ones that warrant revision, with revision of "There are numbers" following as a consequence.

${ }^{7}$ For instance, we see claims that the 'Quinean method is eliminativist by design' (Schaffer 2009, 372). Similarly Thomasson (2007) runs her critique of eliminativism together with a critique of Quineanism.

${ }^{8}$ Schaffer doesn't make it sufficiently clear here that this will be a list of kinds. Contrary to what some have suggested, the Quinean has no particular interest in the question "How many things are there?" - just as well, since that isn't likely to be answerable by any research programme that could be meaningfully undertaken by finite beings.

9 Quine (1951) gives an example of two theories of real numbers which agree on what there is, but where one has sentences translatable as "the real number $x$ is a whole number" and the other doesn't, which is important because it has implications for the theory's (in)completeness.

${ }^{10}$ It is crucial to note that here I am putting Quine's own views about modality to one side. Quine's scepticism about modality is distinct from his general methodology - the latter can be adopted even if one sees the former as untenable or unnecessary, as a great many philosophers now do. The weighing-up of the usefulness of the ontology-heavy and the ideology-heavy theories can be Quinean, even though the theories themselves do not chime perfectly with Quine.

${ }^{11}$ Much discussion of explication proceeds on that basis, considering its use in tidying up the 
practice of science: see, e.g., Maher (2007); Brun (2016).

${ }^{12}$ This focus on regimentation is to some extent suggested by Gustafsson (2013), where it plays a significant role in distinguishing the place of explication in Carnap's project from its place in Quine's, but his 2006 shows a view of explication much more in concert with that given here. I have some points of disagreement with Gustafsson, in particular regarding the extent to which Quine's and Carnap's differences are manifested in different attitudes to explication, but that discussion goes beyond the remit of this paper.

${ }^{13}$ Another way to clarify things would be to note that Quine's method can be seen as analogous to a rational reconstruction, as he observes in his $(1995,16)$. I leave this as a note to postpone the substantial task of comparing this to, and distinguishing this from, other rational reconstructive projects

${ }^{14}$ It bears saying, in relation to the earlier discussion of explication versus regimentation, that Moore's talk of the correct analysis would be problematic for Quine; we should rather speak either of the best, or of $a$ good analysis.

${ }^{15}$ The fact that the truth of (2) might be under threat if we choose the explaining away characterisation shows that there is some difference between the two regarding whether ordinary language is left undisturbed. Contrary to some accounts, Quine does care about ordinary language, since it is where we begin from, but it's certainly not authoritative. It belongs within the mix of our overall theory.

${ }^{16} \mathrm{I}$ of course have no stake here in the attempt to explain/repudiate the mental; my point is entirely independent of that dispute. It's worth noting though that while Quine was optimistic in earlier work (e.g. Quine 1960) about the prospects for this reduction, in the cited work he acknowledges that it isn't promising and acquiesces in anomalous monism.

${ }^{17} \mathrm{I}$ am here neutral between different accounts of explanation. Precisely what kind of explanation we are dealing with is left open; there is much of interest to be said on this, so much that it cannot be dealt with here. However if, as some have supposed, the only way to make sense of a notion of metaphysical explanation is through grounding, that sort of explanation would not be countenanced by the account envisaged here.

${ }^{18} \mathrm{My}$ sincere thanks to two anonymous referees, whose insightful comments were very helpful 
in clarifying several points in the paper.

\section{References}

Brun, Georg. "Explication as a Method of Conceptual Re-Engineering." Erkenntnis 81, 6: (2016) 1211-1241.

Carnap, Rudolf. Meaning and Necessity. University of Chicago Press, 1947.

Daly, Chris, and David Liggins. "In defence of existence questions." Monist 97(4): (2014) 460-478.

Ebbs, Gary. "Carnap and Quine on Truth by Convention." Mind 120(478): (2011) $193-237$.

Egerton, Karl. "Getting Off the Inwagen: A Critique of Quinean Metaontology." Journal for the History of Analytical Philosophy 4, 6: (2016) 1-22.

—. "Found guilty by association: in defence of the Quinean criterion." Ratio 31: (2018) 37-56.

Eklund, Matti. "Metaontology." Philosophy Compass 1(3): (2006a) 317-334.

—. "Neo-Fregean Ontology." Philosophical Perspectives 20: (2006b) 95-121.

Fine, Kit. "The Question of Realism." The Philosophers' Imprint 2(1): (2001) $1-30$.

. "The Question of Ontology." In Metametaphysics, edited by David Chalmers, David Manley, and Ryan Wasserman, Oxford University Press, 2009. 
Gustafsson, Martin. "Quine on Explication and Elimination." Canadian Journal of Philosophy 36: (2006) 57-70.

—. "Quine's Conception of Explication - and Why It Isn't Carnap's." In $A$ Companion to W. V. O. Quine, edited by Gilbert Harman, and Ernie Lepore, Oxford: Wiley-Blackwell, 2013.

Hirsch, Eli. "Physical-Object Ontology, Verbal Disputes, and Common Sense." Philosophy and Phenomenological Research 70(1): (2005) 67-97.

Hylton, Peter. Quine. Routledge, 2007.

van Inwagen, Peter. "Meta-Ontology." Erkenntnis 48(2/3): (1998) 233-250.

_. "Being, Existence, and Ontological Commitment." In Metametaphysics, edited by David Chalmers, David Manley, and Ryan Wasserman, Oxford University Press, 2009.

Jenkins, C. S. "What is Ontological Realism?" Philosophy Compass 5(10): (2010) 880-890.

Koslicki, Kathrin. "Varieties of ontological dependence." In Metaphysical Grounding: Understanding the Structure of Reality, edited by Fabrice Correia, and Benjamin Schneider, Cambridge: Cambridge University Press, 2012.

—. "Questions of Ontology." In Ontology After Carnap, edited by Stephan Blatti, and Sandra Lapointe, Oxford University Press, 2016.

Lewis, David. "Elusive knowledge." Australasian Journal of Philosophy 74(4): (1996) 549-567. 
Maher, Patrick. "Explication Defended." Studia Logica 86: (2007) 331-341.

Manley, David. "Introduction: a guided tour of metametaphysics." In Metametaphysics, edited by David Chalmers, David Manley, and Ryan Wasserman, Oxford University Press, 2009.

Moore, G. E. "A defence of common sense." In Philosophical Papers, New York: Macmillan, 1959.

Price, Huw. "Metaphysics After Carnap: the ghost who walks?" In Metametaphysics, edited by David Chalmers, David Manley, and Ryan Wasserman, Oxford University Press, 2009.

Quine, W. V. "On What There Is." Review of Metaphysics 2: (1948) 21-38.

—. "Ontology and ideology." Philosophical Studies 2(1): (1951) 11-15.

. Word $\&$ Object. Cambridge, MA: MIT Press, 1960.

—. "Ontology and Ideology Revisited." The Journal of Philosophy 53(9): (1983) 499-502.

—. From Stimulus to Science. Harvard University Press, 1995.

Schaffer, Jonathan. "On What Grounds What." In Metametaphysics, edited by David Chalmers, David Manley, and Ryan Wasserman, Oxford University Press, 2009.

Thomasson, Amie. Ordinary Objects. Oxford University Press, 2007. 